\title{
The Load Capability of Piezoelectric Single Crystal Actuators
}

\author{
Tian-Bing $\mathrm{Xu}^{1}$, Ji Su${ }^{2}$, Xiaoning Jiang ${ }^{3}$, Paul W. Rehrig ${ }^{3}$, and Wesley S. Hackenberger ${ }^{3}$ \\ ${ }^{1}$ National Institute of Aerospace, 144 Research Drive, Hampton, VA 23666, USA \\ ${ }^{2}$ NASA Langley Research Center, Hampton, VA 23681, USA \\ ${ }^{3}$ TRS Technologies, Inc., 2820 East College Avenue, State College, PA 16801, USA
}

\begin{abstract}
Piezoelectric lead magnesium niobate-lead titanate (PMN-PT) single crystal is one of the most promising materials for electromechanical device applications due to its high electrical field induced strain and high electromechanical coupling factor. PMN-PT single crystal-based multilayer stack actuators and multilayer stack-based flextensional actuators have exhibited high stroke and high displacement-voltage ratios. The actuation capabilities of these two actuators were evaluated using a newly developed method based upon a laser vibrometer system under various loading conditions. The measured displacements as a function of mechanical loads at different driving voltages indicate that the displacement response of the actuators is approximately constant under broad ranges of mechanical load. The load capabilities of these PMN-PT single crystal-based actuators and the advantages of the capability for applications will be discussed.
\end{abstract}

\section{INTRODUCTION}

Electromechanical actuators with large stroke, high precision, and high mechanical load capability are important for shape control, precision positioning, and force control in various NASA, military and civilian applications [1, 2]. In the past decades, a great deal of effort has been devoted to developing smart materials and structures with those desired features [3-8]. A broad range of actuation approaches have been developed, including electro-magnetic, electrostatic, piezoelectric, electrostrictive, magnetostrictive, shape memory alloy, and thermal pneumatic [9]. Among these kinds of actuators, the advantages of the solid state piezoelectric actuators are large electromechanical energy conversion efficiency, broad operation frequency range, small heat generation and no electromagnetic noise. However, the disadvantage of this kind of actuator is that it has small stroke. In the 1990s, the relaxor-based single-crystal piezoelectric materials, such as $\mathrm{Pb}\left(\mathrm{Mg}_{\mathrm{x}} \mathrm{Nb}_{1-\mathrm{x}}\right) \mathrm{O}_{3}-\mathrm{PbTiO}_{3}(\mathrm{PMN}-\mathrm{PT})$ and $\mathrm{Pb}\left(\mathrm{Zc}_{\mathrm{x}} \mathrm{Nb}_{1-\mathrm{x}}\right) \mathrm{O}_{3}-\mathrm{PbTiO} 3$ (PZN-PT) with high strain and piezoelectric constant, were discovered $[5,10]$. In the meantime, Newnham et al. [11] invented the concept of flextensional actuator/transducer to achieve the amplification of the displacement response. Recently, the piezoelectric PMN-PT single-crystal multilayer stack actuators and the multilayer stack-based flextensional actuators were developed at TRS [12]. These actuators demonstrated larger stroke and higher precision even at a broad range of temperatures ( $<20$ to $300 \mathrm{~K}$ ) than the conventional piezoelectric ceramic-based actuators. This paper focuses on the study of the load capability of these two actuators, and presents a load capability characterization method. The experimental results demonstrated that the two actuators keep constant displacement at a broad range of mechanical loads. 


\section{LOAD CAPABILITY CHARACTERIZATION METHOD}

A diagram of the load capability measurement setup is shown in Fig. 1. The actuator was bonded on a test fixture (A $125 \mathrm{~mm}$ X125 mm X $13 \mathrm{~mm}$ plate), shown as in Fig. 1 (b), mechanically fixed on a 3-D stage with 5 minutes epoxy. The mass set was on the top of the measured actuator and attached with a piece of double tape. The mass center and the center of the actuator were aligned in one line to stabilize the mass. A piece of Polytec reflective tape (Polytec PI, Inc.) was attached on the center of the mass (or on center of the actuator for the case of load $=0$ ). The displacements were measured utilizing a laser vibrometer. In order to increase the resolution of the laser vibrometer, a lock-in amplifier was used to pickup the signal as shown in Fig. 1 (a). With a lock-in amplifier, the displacement resolution of the laser vibrometer system can go down to $0.5 \mathrm{~nm}$.
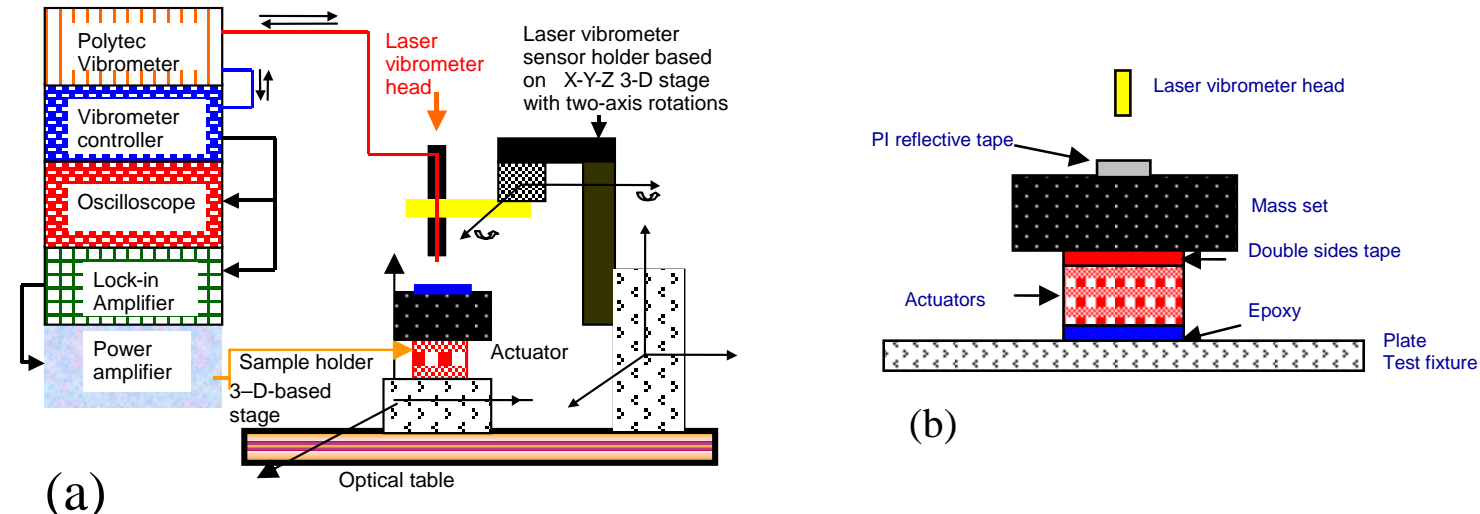

(b)

Fig. 1. Diagram of the load capability test setup. (a) Overall measurement setup and (b) detail of the mass set applied on the actuators during measurements

(a)
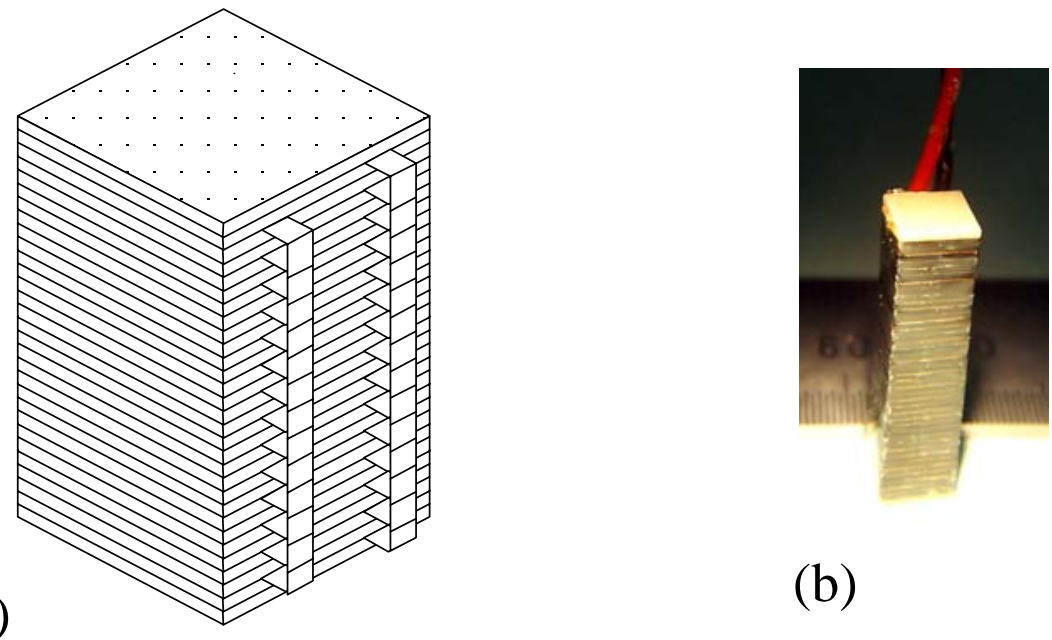

(b)

Fig. 2. Piezoelectric single crystal multilayer stack actuator. (a) Diagram of the multilayer stack, and (b) picture of the multilayer stack actuator 


\section{LOAD CAPABILITY OF MULTILAYER STACK ACTUATOR}

The piezoelectric single crystal multilayer stack actuator is shown in Fig. 2. The parameters of the stack actuator are listed in Table 1. In order to eliminate the depoling effect on the piezoelectric single crystals, the single crystal stack actuator must be operated at a positive voltage. Since the laser vibrometer is measuring the dynamic motion only, a DC bias voltage and AC sinusoidal voltage were combined to drive the actuator. A $300 \mathrm{~V}$ DC bias is applied during measurement. The AC signal ranged from 0 to $200 \mathrm{~V}_{\mathrm{rms}}$ [566 $\mathrm{V}_{\mathrm{pp}}$ (peak to peak value), 1 $\mathrm{V}_{\mathrm{rms}}=2 * 2^{0.5} \mathrm{~V}_{\mathrm{pp}}$ ]. The measurement frequency is $0.5 \mathrm{~Hz}$.

The measured displacement as a function of load at different AC signal is presented in Fig. 3. The displacements are almost constant in the measured load range for a given voltage. The comparison of displacements as a function of AC signal for the load-free case and with $3.07 \mathrm{~kg}(6.8 \mathrm{Lb})$ load is shown in Fig. 4. The displacement reduction is very small for the actuation with $3.07 \mathrm{~kg}$ load.

The measured results indicate that the piezoelectric single crystal multilayer stack actuator has a high mechanical load capability for motion controls.

Table 1. Parameters of stack actuator

\begin{tabular}{|c|c|c|c|c|c|}
\hline \multicolumn{3}{|c|}{ Dimensions } & layers & Thickness of each layer & Drive voltage range \\
\hline Length & width & height & & & \\
\hline $10 \mathrm{~mm}$ & $10 \mathrm{~mm}$ & $20 \mathrm{~mm}$ & 42 & $0.5 \mathrm{~mm}$ & $0 \mathrm{~V}-1000 \mathrm{~V}$ \\
\hline
\end{tabular}

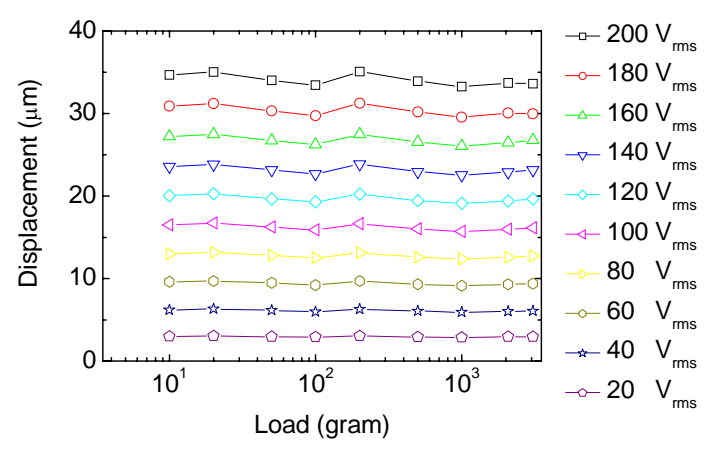

Fig. 3. Displacements as a function of load for single crystal stack actuator at different AC signal with $300 \mathrm{~V}$ DC bias.

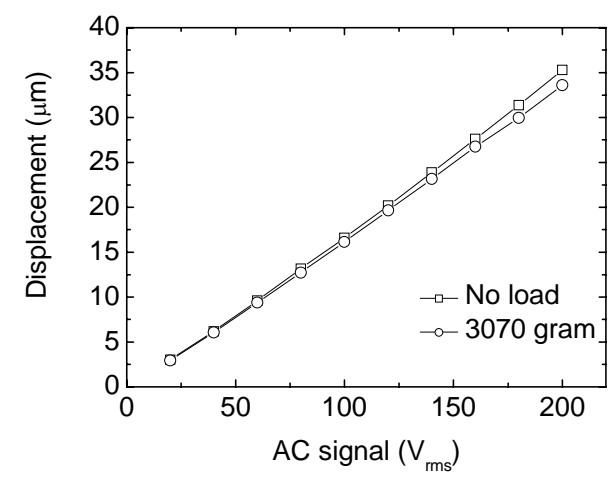

Fig. 4. Displacements as a function of applied AC voltage with $300 \mathrm{~V}$ DC bias at different load 


\section{LOAD CAPABILITY OF SINGLE CTRYSTAL STACK-BASED FLEXTENSIONAL ACTUATOR}

The diagram of the piezoelectric single crystal multilayer stack-based flextensional actuator is shown in Fig. 5 (a). The deformation of the multilayer stack in the $X$ direction will be amplified to be a large displacement in the $Z$ direction by the metal shell of the flextensional actuator. The amplification of the flextensional actuator is dependent on the geometry of the metal shell [13]. The picture of a real flextensional actuator is presented in Fig. 5 (b). The parameters of the measured flextensional actuator are listed in Table 2.

In order to eliminate the depoling effect of the piezoelectric single crystal, the flextensional actuator must be operated at a positive voltage. Since the laser vibrometer is measuring the dynamic motion only, a DC bias voltage and an AC sinusoidal voltage were combined to drive the actuator. A $200 \mathrm{~V}$ DC bias was applied during measurement. The AC driving voltage ranged from 0 to $120 \mathrm{~V}_{\mathrm{rms}}\left(340 \mathrm{~V}_{\mathrm{pp}}\right)$. The measurement frequency was $1 \mathrm{~Hz}$.

The measured displacement (peak to peak) as a function of load at different AC driving voltage is presented in Fig. 6. The displacements are almost constant over the measured load range for a given voltage applied.

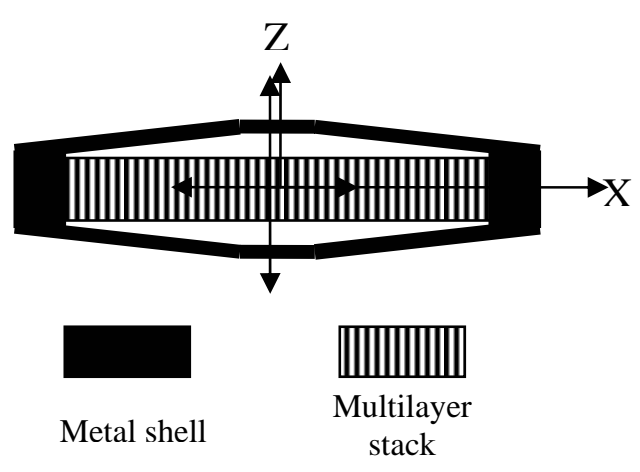

(a)

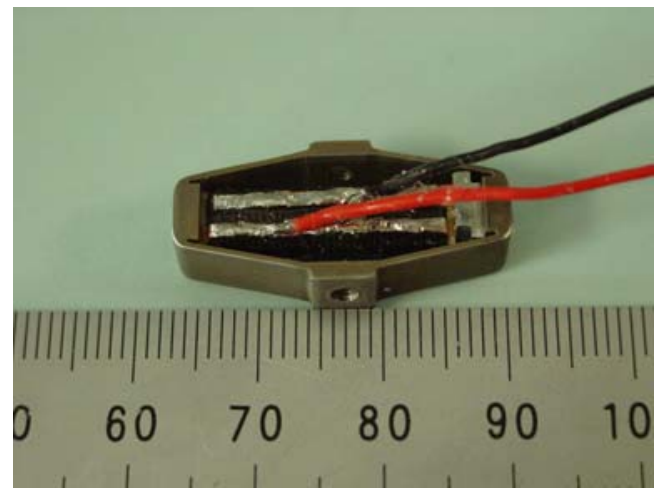

(b)

Fig. 5. Piezoelectric single crystal multilayer stack-based Flextensional actuator (a) Diagram of the actuator, and (b) picture of the real flextensional actuator.

Table 2. Parameters of flextensional actuator

\begin{tabular}{|c|c|c|c|c|c|c|}
\hline \multicolumn{4}{|c|}{ Dimensions } & \multirow[t]{2}{*}{ layers } & \multirow{2}{*}{$\begin{array}{c}\text { Thickness of } \\
\text { each layer }\end{array}$} & \multirow{2}{*}{$\begin{array}{l}\text { Drive voltage } \\
\text { range }\end{array}$} \\
\hline & Length & width & height & & & \\
\hline Active element & $15 \mathrm{~mm}$ & $5 \mathrm{~mm}$ & $5 \mathrm{~mm}$ & 30 & $0.5 \mathrm{~mm}$ & $0 \mathrm{~V}-500 \mathrm{~V}$ \\
\hline $\begin{array}{c}\text { Overall of the } \\
\text { flextensional actuator }\end{array}$ & $27 \mathrm{~mm}$ & $10 \mathrm{~mm}$ & $13.5 \mathrm{~mm}$ & & & \\
\hline
\end{tabular}


A comparison of displacements as a function of AC driving voltage without load and with $3.07 \mathrm{~kg}(6.8 \mathrm{Lb})$ load is shown in Fig. 7. There is no significant displacement reduction obtained for the actuation with $3.07 \mathrm{~kg}$ load.

The experimental results indicate that the piezoelectric single crystal multilayer stackbased flextensional actuator at a given driving voltage, exhibits the same displacement over a wide range of mechanical loads. This demonstrated that the single crystal-based flextensional actuator has load capability. This experiment gives us confidence to apply the piezoelectric single crystal multilayer stack-based flextensional actuator to various dynamic control applications.

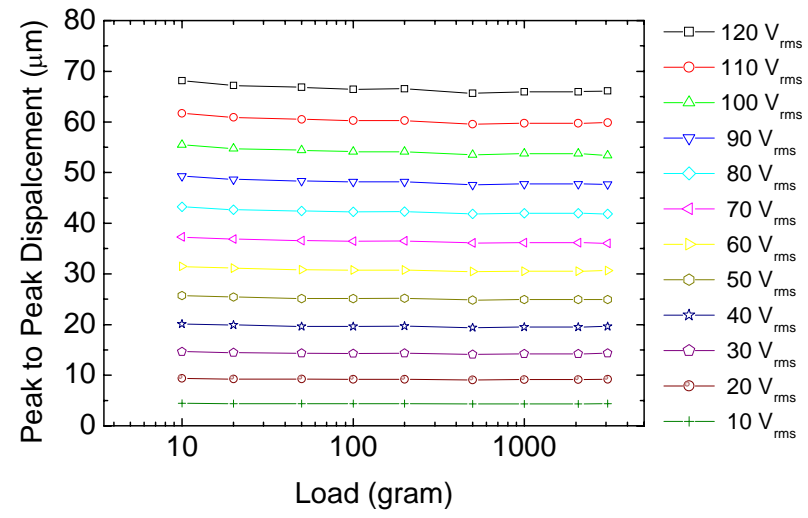

Fig. 6. Peak to peak displacement as a function of load for single crystal flextensional actuator at different AC (1 Hz) driving voltages with $200 \mathrm{~V} \mathrm{DC}$ bias.

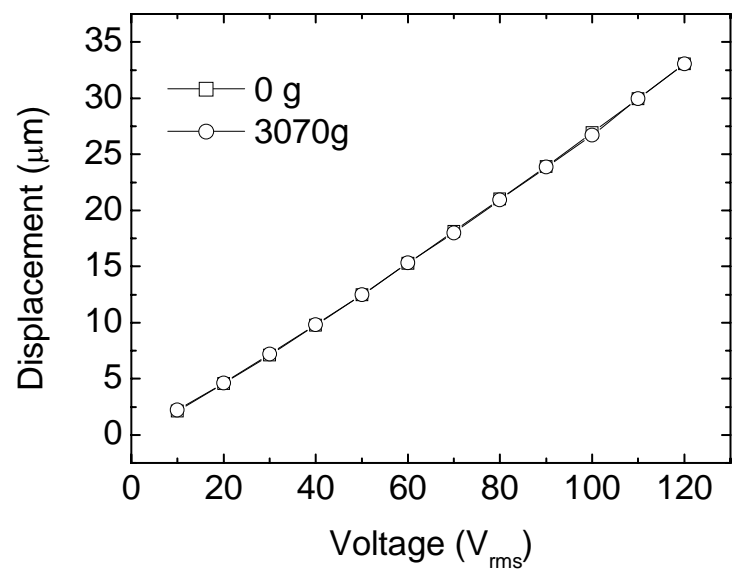

Fig. 7. Displacements as a function of applied AC voltage at two different loads. 


\section{SUMMARY}

In summary, a new mechanical load capability characterization method for actuators was developed. This method can be used to more effectively evaluate a wide range of solid state actuators. The mechanical load capability of the piezoelectric single-crystal multilayer stack actuator and the multilayer stack-based flextensional actuator were evaluated. The experimental results indicate that the displacement responses of the two actuators stay almost constant at a broad range of mechanical loads. This feature of the two kinds of actuators demonstrated that they may be useful for various mechanical controls.

\section{REFERENCES}

1. K. Uchino, Piezoelectric Actuators and Ultrasonic Motor, Boston, Kluwer, 1997

2. Yuhuan Xu, Ferroelectric materials and their applications, Elsevier Science Publishers B.V., North-Holland, 1991

3. L. E. Cross, "Ferroelectric ceramics: Materials and application issues", Ceramic Trans. Vol. 68, pp. 15-55, 1996.

4. R.E. Newnham, "Composite Electroceramics," Ann. Rev. Mat. Sci. Vol. 16, pp. 47-68, 1986

5. S.-E. Park, and T. R. Shrout "Ultrahigh Strain and piezoelectric behavior in relaxor based ferroelectric single crystal”, J. Appl. Phys., Vol. 82, No. 4, pp. 1804-1811, 1997

6. Z. Ma, J. I. Scheinbein and B. A. Newman, "High field electrostrictive response of polymers”, J. Polym. Sci. Part B, Polym. Phys. Vol. 32, pp. 2721-2731, 1994.

7. R. E. Pelrine, R. D. Kornbluh, and J. P. Joseph, "Electrostriction of polymer dielectrics with compliant electrodes as a mean of actuation”, Sens. Actuators A, Vol. 64, pp.77-85, 1998

8. J. Su, Q.M. Zhang, and R.Y. Ting "Space-charge-enhanced electromechanical response in thin-film polyurethane elastomers," Appl. Phys. Lett., Vol. 71, no. 3, pp. 386-388, 1997

9. Q-M Wang, "Piezoelectric ceramic actuators and composite structure for active noise control applications,” Ph. D. Thesis, Penn State University 1998.

10. S. F. Liu, S. E. Park, L. E. Cross, and T. R. Shrout, J. Appl. Phys. 92 (1), 461 (2002).

11. R. E. Newnham, Q. C., Xu, and S. Yoshikawa, United State Patent, \# 4,999,819 (1991), and \# 5,276,657 (1994).

12. S. C. Woody, S. T. Smith, X. Jiang, and P. W. Rehrig, "Performance of single crystal $\mathrm{Pb}(\mathrm{Mg} 1 / 3 \mathrm{Nb} 2 / 3)-32 \% \mathrm{PbTiO}$ stack actuators with application to adaptive structures," Review of Science Instruments 76, 2005, \# 075112

13. R. J. Meyer Jr., A. Dogan, C. Yoon, S. M. Pigrim, and R. E. Newnham, "Displacement amplification of electroactive materials using the cymbal flextensional transducer," Sensors and Actuators A, Vol. 87, 2001, pp. 157-162. 